\title{
Revisiting the LCA+DEA method in fishing fleets. How should we be measuring efficiency?
}

\section{Abstract}

Life Cycle Assessment and Data Envelopment Analysis have been repeatedly combined in the literature as LCA+DEA method with the aim of enhancing the utility of life-cycle based methods in order to account for eco-efficiency verification and environmental impact minimization. Despite its evolution through time, it lacks specific standards that norm the combination of the two methods. In this sense, this study noted that its development has evolved in the frame of mainstream cultural perspectives to measure environmental impacts (i.e., hierarchist approaches). Therefore, the main objective of the study is to compare the benchmarking results obtained through DEA computation using different Cultural Theory approaches to calculate environmental impacts. For this, a case study for the Cantabrian purse seining fishing fleet was chosen. Hence, three different DEA matrices were constructed attending to the three main human visions on environmental issues: hierarchist, individualist and egalitarian. All three matrices represented the same set of inputs to be optimized, but differed in the nature of the output flow, representing landed fish, energy content or biomass removal. Results suggest that optimization of environmental impacts is strongly influenced by the cultural perspective selected. In the particular case of fishing fleets, benchmarking environmental impacts based on anthropocentric views may be ignoring the health of fishing stocks and the trophic complexity of the ecosystems. Methodological conclusions are directed towards the need to define more flexible and holistic frameworks in LCA+DEA modelling with the aim of enrichening the set of predetermined assumptions, including the Cultural Theory, to avoid biased interpretations.

Keywords: anthropocentric perspective; Cultural Theory; Data Envelopment Analysis; ecocentric perspective; Life Cycle Assessment; pelagic fisheries. 


\section{Introduction}

Fish managers have relied on observation and research in past decades to face the challenge of improving the sustainability of dwindling fish stocks in European fisheries [1] [2]. This has led to the definition of a complex fisheries management system which is imposed through relatively strict quota systems to control landings of the main fish species, as well as the development of legislation to adapt the amount and capacity of fishing vessels in fleets to the available fish stocks [3]. Based on this scenario, numerous studies have dealt with improving the performance of fishing fleets in terms of technical efficiency and capacity [4]. In this context, the Food and Agricultural Organization of the United Nations (FAO) determined that Data Envelopment Analysis (DEA), a non-parametric linear programming method to analyze the efficiency of multiple-unit systems, constitutes an adequate method to evaluate fishing capacity [5].

Nevertheless, recent studies have also been developed in terms of ensuring that efficiency is also achieved from an environmental sustainability perspective [6], based on the assumption that vessels can lower the operational inputs and, therefore, reduce the environmental impact of their activities, while maintaining the same catch levels [6] [7] [8]. For this, DEA has been combined with Life Cycle Assessment (LCA), an internationally standardized methodology that identifies the environmental impacts that are generated through the life-cycle of supply chains [9].

LCA has been repeatedly used in fisheries and seafood supply chains for over a decade as an important mechanism to elongate the current shift from single-species stock assessment to ecosystem-based frameworks, by including additional environmental impacts at a global scale, such as global warming or depletion of abiotic resources [10] [11]. Given its holistic nature, integrating a wide range of environmental burdens that are characterized in impact categories, it has been shown to be an adequate decision support tool in fisheries [12]. However, 
1 LCA has shown certain limitations when it comes to monitoring the environmental

2 performance of multiple units that present the same function. Therefore, the so-called

3 LCA+DEA method has been developed to expand the utility of life-cycle based methods in

4 order to account for eco-efficiency verification and environmental impact minimization across

5 complex sectoral systems [9].

6 The LCA+DEA method, when applied to fisheries, has traditionally undergone an

7 input-oriented approach, with the aim of reducing the reliance on energy and raw materials

8 while maintaining landings. Nonetheless, this minimization has mostly been based on a

9 perspective in which the round fresh landings are considered on the basis of their gross mass

10 weight [6] [13], and occasionally considering the economic revenue linked to these landings

11 [8]. However, the present study argues that minimization of operational inputs in LCA+DEA studies may deserve further analysis in terms of the output that is used for the optimization. In other words, this minimization can be interpreted in different ways depending on what is considered the main output of the production system. For instance, it could be argued that the main function of fishing vessels may not be to maintain the level of gross weight landings, but to maintain or optimize the economic revenue, the gross energy or the protection of marine biodiversity.

Consequently, the main aim of this research article is to understand how different perspectives on how to generate operational benchmarks for fishing fleets using the LCA+DEA method can alter the final results obtained and their interpretation. More specifically, these varying approaches will focus on how input/output material and energy flows are managed in the combined method, with the main objective of not only informing on eco-efficiency considerations, but also on sustainable scale-oriented environmental management through the identification of adequate biophysical flows. For this, the selected case study was a group of 
1 (Spain). These multiple units form part of a relatively homogeneous fleet/fishery fulfilling the

2 purpose of landing fish species from the Cantabrian Sea stock, which is thereafter destined

3 mainly to direct human consumption (DHC). The results of the study are intended to be of

4 utility for fish managers, as well as for LCA and DEA practitioners seeking new approaches to

5 improve the assessment of eco-efficiency and sustainability in fishing fleets.

\section{2. Materials and Methods}

$7 \quad 2.1 \quad$ Benchmarking objectives of LC+DEA methods

When multiple inventory data are available in a life-cycle (LC) oriented study, a common solution is to establish an average inventory which includes the average values for the different inputs and outputs. Nonetheless, the high degree of variability reported by standard deviations is an important barrier [6]. While this approach is useful for many purposes, it poses problems to communicate the specific actions that individual units could implement to foster their environmental efficiency. To deal with this problem, the use of DEA allows quantifying in an empirical manner the comparative productive efficiency of multiple similar entities named Decision Making Units (DMUs) [14].

Current LC+DEA methods for the benchmarking of multiple DMUs can be divided into two main blocks: those that are focused on the benchmarking of environmental indicators, and those that provide benchmarks through the computation of energy methods [9]. Regarding the former, the joint application of the LCA+DEA method carries a series of synergistic effects related to the link between operational efficiency and environmental impacts.

On the other hand, the available energy LC+DEA methods can be classified according to their anthropocentric or ecocentric perspective. Anthropocentric alternatives include cumulative energy demand (CED) and cumulative exergy demand (CEDxD) ${ }^{1}$ coupled with

\footnotetext{
${ }^{1}$ Exergy is defined as the maximum amount of useful work, which can be done by a system, or energy flow as it comes to equilibrium with a reference environment. The cumulative exergy demand denotes how much resource of the ecosphere has to be exploited in processing a product [41].
} 
1 DEA. These methods essentially evaluate the cumulative use of natural resources by

2 considering their energy or exergy contents (user-side perspective). Ecocentric approaches

3 consider the emergy (Em) concept, which is an approximation of the solar energy previously

4 provided to generate a product and/or to support a system and its level of organization [15].

5 Moreover, emergy evaluates the resources according to the total (solar) energy involved in their

6 formation [16]. All these energy LC+DEA methods involve similar steps, but different

7 techniques to analyze the life cycle inventory (LCI) data in energy terms.

More specifically, it has been noted that the function that is described in LCA+DEA case studies tends to stick to an anthropogenic perspective of supply chains, prioritizing the market exchange that occurs (e.g., maximization of economic revenue, productivity, production, or minimization of operational inputs), with a myopic view of the underlying environmental flows that are engendered. The choice of a particular perspective provokes inevitable uncertainties in LCA studies. Assumptions can derive from lack of knowledge, whereby the choice of one option over another can be influenced by personal beliefs and values that reflect what we care about [17].

Within LCA, the Cultural Theory developed by the anthropologist Mary Douglas (1982) has been used to define different modeling scenarios, as it reflects both visions of society and views on nature. This theory established that there are five existing "ways” of life or cultural theories to face environmental problems such as climate change, namely the individualist, the hierarchist, the egalitarian, the hermit and the fatalist. Each perspective reflects a hypothetical stakeholder or decision maker with a specific set of preferences and contextual values. The stereotypical individualist is a self-made person, free from control by others, who strives to impose order on his or her environment. Generally, they tend to oppose "top-down" interventions by the state or any other authority, preferring instead personal responsibility and freedom of choice. Hierarchists prefer to regard nature as tolerant within definable limits, 
1 which can be manipulated by incorporating ecological principles into all management

2 approaches and accounting techniques. This perspective coincides with the view that impacts

3 can be avoided with proper management, seeking a balance between manageability and the

4 precautionary principle. Egalitarians regard the fragility of nature as part of their reason for

5 existence. This vision gives high priority to the precautionary principle and equal importance

6 to present and future effects. Fatalists tend to see nature as a lottery, opening and closing

7 options and acting in unpredictable ways. Finally, hermits, also referred to as autonomists,

8 escape any influence from society or social level and detach from what happens in the world

9 [18]. Van Asselt and Rotmans (1996) [19] proposed to use these ethical attitudes to investigate

10 alternative model routes for decision-making. In general, it is assumed that only the first three

11 perspectives play part in environmental decision-making and, thus, LCA: the individualist,

hierarchist and egalitarian perspectives. Both fatalist and hermit perspectives were excluded

because they cannot systematically be described by any characteristic function and, moreover,

they are considered to have marginal or no influence in environmental decision-making. The

Cultural Theory is attractive to be applied in LCA, as it both reflects visions on society and views on nature and aides in the interpretation of results whenever trade-offs throughout environmental indicators are evident. In fact, several studies applied the Cultural Theory in life cycle thinking, showing the practicability of the approach [20] [21] [22].

Based on the existing LC+DEA literature, it was hypothesized that LCA+DEA has

focused on a hierarchist approach due to the fact that it is an intermediate perspective in which the temporality is balanced based on a consensus about the short- and long-term damages [17]. However, it should be noted that some Life Cycle Impact Assessment (LCIA) methods, such as IPCC, Eco-Indicator 99 or ReCiPe², include in their computation these cultural theories.

\footnotetext{
${ }^{2} \mathrm{ReCiPe}$ provides a recipe to calculate life cycle impact category indicators. The acronym also represents the initials of the institutes that were the main contributors to this project and the major collaborators in its design: National Institute for Public Health and the Environment (RIVM) and Radboud University, CML and PRé [25].
} 
1 Several authors have discussed this issue in the literature. Schryver and colleagues [17] [23],

2 for instance, analyzed the influence of value choices in impact assessment models for human

3 health following the Cultural Theory. Similarly, Pushkar (2013) [24] used the different

4 perspectives based on the Cultural Theory that the Eco-Indicator 99 methodology considers to

5 perform the evaluation of building technologies under LCA uncertainties.

6 In this study, the ReCiPe LCIA method was used, which includes hierarchist,

7 egalitarian and individualist perspectives, with the aim of identifying potential distortions in

8 the LCA results that may ultimately affect the evaluation of the eco-efficiency of the Cantabrian

9 purse seining fleet that is assessed.

$10 \quad 2.2$ Selection of the LCA+DEA method

11 The "modified five-step LCA+DEA method" developed by Iribarren et al. (2010) [8] and refined in Avadí et al. (2014) [13] was used following the next steps, as represented in Figure 1: i) development of the LCI for each of the DMUs (data collection); ii) performance of the LCIA for every DMU and definition of the subsystems included as inputs in the DEA matrix; iii) determination of the operational efficiency for each DMU; iv) LCIA of the target DMUs (virtual units); and, v) quantification of the environmental consequences of operational inefficiencies. This method, instead of including specific operational inputs in the DEA matrix (i.e., steel, ice, antifouling, etc), uses the weighted ReCiPe endpoint LCIA method [25] to attain a final indicator value for a cluster of operational activities. Therefore, different subsystems were created to cluster those operational items that show resembling roles within the vessel's functioning (i.e., construction items, such as hull material and engines). 


\subsection{Selection of the DEA model}

The selected DEA model was the slacks-based measure of efficiency (SBM). The choice of model was based on its flexibility concerning the computation of the individual entities (i.e., DMUs) irrespective of the units of measure that are used for the different inputs/outputs [13]. However, when a DEA analysis is performed, three factors have to be taken into account: i) metrics (radial or non-radial); ii) orientation (toward inputs, toward outputs or mixed orientation); and, iii) the display of the production possibility set (PPS). Regarding the latter, even though DEA does not rely on assumptions that the data come from any specific production function, some assumptions are usually made to perform DEA. The three common assumptions are convexity, scalability, and free disposability of inputs and outputs. When the three assumptions are made, a constant return to scale (CRS) approach is assumed. On the other hand, if convexity and free disposability, but not scalability are assumed, then variable returns to scale (VRS) approach is employed [6]. Previous LCA+DEA studies for fisheries and extensive aquaculture have considered a CRS approach [6] [26] [27], taking into account that all the vessels have similar technical characteristics, target the same types of fishing species and operate under the same regulations in one single fishing stock [28]. Nevertheless, for the sake of further discussion, the CRS and VRS approaches are computed in parallel in the current study. Moreover, as mentioned above, the LCA+DEA method when applied to fisheries, has traditionally undergone an input-oriented approach.

\subsection{Input and outputs selection for the DEA matrices}

A total of three different DEA matrices were computed in this study. Each DMU was structured by including four different inputs. On the one hand, the annual amount of diesel consumed by the fishing vessels was computed in $\mathrm{kg} /$ year (input 1). On the other hand, the remaining inputs, as mentioned previously, do not refer to individual operational inputs, but to three distinct subsystems: construction (input 2), use (input 3) and maintenance (input 4) phases 
1 of the vessel's life cycle (see Figure 2). To obtain the inputs 2, 3 and 4 of each DEA matrix, the

2 construction, use and maintenance phases of the vessels were modelled with the software

3 SimaPro 8.2 [29]. The three endpoint perspectives proposed by the ReCiPe environmental

4 method (i.e., individualist (I), hierarchist (H) and egalitarian (E)) [25] were computed and the

5 value of the endpoint single score (SS) obtained was employed as the input. These endpoint

6 perspectives compile 18 impact categories in three different areas of protection: human health,

7 resources availability and ecosystem diversity. To obtain the SS, it is necessary to normalize

8 and weight the three areas of protection composed by the different impact categories (damage

9 to human health, damage to ecosystems and damage to resource availability). Depending on

10 the ReCiPe approach selected (individualist, hierarchist and egalitarian) the normalization

11 threshold values and the weighting factors are different. These values were collected in Table

12 1. However, it should be highlighted that this normalization only affects the internal computation in the calculation of the inputs with LCA modelling, whereas no normalization was carried out within the DEA matrix between inputs.

These perspectives do not claim to represent archetypes of human behavior, but they are merely used to group similar types of assumptions and choices as explained in section 2.1 [25]. For instance:

- Perspective I is based on the short-term interest, impact types that are undisputed, technological optimism as regards human adaptation.

- Perspective $\mathrm{H}$ is based on the most common policy principles with regards to timeframe and other issues. It is a utilitarian approach in which the minimization of pain and the optimization of welfare is enhanced. 
- Perspective $\mathrm{E}$ is the most precautionary perspective, taking into account the longest time-frame, impact types that are not yet fully established but for which some indication is available, etc.

In the current study, these three endpoints perspectives proposed by ReCiPe environmental method are merged with each one of the three outputs alternatives of the DEA matrices:

1) Kilograms of landed captures per year, which were obtained directly from the data reported by the vessels included in the sample.

2) Energy obtained from protein fish per year. The energy from protein fish was calculated based on the protein content of fish. The embodied energy of fish was calculated based on the maximum edible content and the protein content per $100 \mathrm{~g}$ of edible portion. The edible content and the protein content of the fish landed by the Cantabrian purse seining fleet were obtained from a database that aggregates these values for over 100 species (Peter Tyedmers, personal communication, September 2011) and shown in Table S1 of the Supporting Material (SM).

3) Removed biomass from ecosystem per year. The removal of biomass was calculated by using the Biotic Resource Use (BRU) impact category implemented by Parker (2011) [31], used to monitor the Primary Production Required (PPR) defined by Pauly and Christensen (1995) [32] (see Equation 1).

$$
P P R=[\text { Catch } / 9] \times 10^{(T L-1)} \quad \text { Eq.1 }
$$

where TL is the trophic level of each fish which are collected in Table S2 of the SM. In this context, perspective I is linked to an output that represents the round weight of landed fish, perspective H uses energy from fish protein as the reference output, and perspective E relates to the removed biomass (see Table 2). In the case of perspective I, output selection is based on the idea that the sustainable management of fisheries is an opportunity for development and business in a robust natural environment. Hence, sustainable development 
1 constitutes an opportunity to continue expanding the economic system. In this particular study,

2 the total kilograms of landed fish were selected as the output for perspective E. Nonetheless, it

3 could be argued that a monetary flow would be a better option to represent economic

4 transactions. However, this perspective was discarded due to several reasons, including: i) the

5 lack of data available regarding the sale price at auction obtained by the different vessels in the

6 year of assessment; ii) the fact that the region of Cantabria does not have a publicly available

7 register of auction sales per species, which contrasts with the region of Galicia which has a

8 detailed daily registrar per species and port [33]; and iii) the notable fluctuation of fish prices

9 on a daily or seasonal basis. In contrast, perspective $\mathrm{E}$ is based on a view that sees the economic

10 system as a threat to a fragile natural environment. Hence, output selection is based on biomass

11 removal as the clearest representation of the threat that the anthroposphere exerts on the natural resource under study. Finally, as a middle view, perspective $\mathrm{H}$ balances conservation, economic profit and human welfare. In this context, it makes sense that the output selected should consider food security through the maximization of energy content of the species landed.

An input-oriented approach was selected for the three matrices in order to minimize inputs while producing at least the given output levels. Nevertheless, the output based on the removed biomass from the ecosystem was represented with the inverse value, since the reference point would be to optimize the inputs considering as low BRU values as the optimum output. Therefore, a SBM-I-C model was chosen for the three matrices studied. The input/output values of the DEA matrices are collected in Tables S3-S5 of the SM. 


\section{$1 \quad 3 . \quad$ Results and discussion}

DEA-Solver Pro was the software used for the computation of the DEA matrices [34].

3 Results using the CRS model are gathered in Table 3, which includes the efficiency score for each DMU. A vessel is deemed inefficient when efficiency score $\phi<1$, whereas $\phi=1$ represents an efficient vessel. When individualist or hierarchist perspectives were considered, a total of 2 vessels (out of 32) were found to operate efficiently. Moreover, in both cases the efficient vessels were the same units (i.e., DMU 20 and DMU 23). These two perspectives, individualist and hierarchist, presented similar efficiency scores for each DMU, ranging from $10 \%$ to 52\% and from $10 \%$ to 53\%, respectively. The average efficiency (including efficient DMUs) of both DEA matrix were similar (see Figure 3): $30.8 \% \pm 20.3 \%$ for I and $32.0 \% \pm 20.3 \%$ for $\mathrm{H}$. Although their inputs (i.e., inputs 2, 3, and 4) were obtained using different ReCiPe approaches, the endpoint SS values in both cases were similar. On the other hand, the results indicate that I and $\mathrm{H}$ approaches applying the VRS model presented very similar average efficiencies to those computed applying the CRS model (see Figure 3): $34.5 \% \pm 18.8 \%$ for I and $36.1 \% \pm 18.7 \%$ for H. Moreover, the efficient DMUs are the same in both cases (DMUs 20 and 23) (see Table 3). A previous study conducted by Avadí et al. (2014) [13], identified that the main carrier of the inefficiencies in the Peruvian purse seining fleet was fuel efficiency. Moreover, fishing companies measure the efficiency of a vessel almost exclusively in terms of its fuel use performance. For these reasons, to observe the relationship between the efficiency, when the I and $\mathrm{H}$ perspectives were used, and the fuel use intensity (FUI), the values calculated for each DMU using the CRS model were displayed; however, the values of $\mathrm{R}^{2}$ obtained were below 0.1. Due to the fact that the use of fuel represented $89 \%$ of the total Global Warming Potential (GWP) [28], the relationship between the GWP and the efficiency of each DMU was also represented. In this case, the values of $\mathrm{R}^{2}$ were 0.34 when the I perspective was used, and 0.37 when the $\mathrm{H}$ perspective was employed (Figure S1 and S2 of SM). Therefore, it can be 
1 considered that the vessel efficiency is related to the use of fuel indirectly, among other aspects

2 such as the production and maintenance of the seine nets. This relationship was not influenced

3 by the DEA model selected because, as previously mentioned, the results obtained for I and $\mathrm{H}$

4 approaches using VRS were similar to the CRS model.

On the other hand, when the egalitarian approach was used with the CRS model, a total

6 of 3 vessels were considered efficient (DMU 9, DMU 16 and DMU 23) (see Table 3). Despite

7 the fact that this approach presented more efficient vessels, most of the efficiency scores were

8 lower than the individualist and hierarchist perspectives, ranging from $4 \%$ to $57 \%$. However,

9 the average efficiency of the entire sample was $33.3 \% \pm 24.9 \%$, higher than for the $\mathrm{I}$ and $\mathrm{H}$

10 perspectives (see Figure 3), but also with a higher standard deviation. It should be highlighted

11 that the majority of vessels which captured tuna presented efficiencies below 20\% (DMU 10,

DMU 24, DMU 25 and DMU 32) due to the fact that its trophic level was considerably higher ( $\mathrm{TL}=4.3$ ) than that of the other species landed. Moreover, the efficient DMUs were those that captured mainly anchovy and sardine because their trophic levels were the lowest (3.10). Nonetheless, a linear relationship was not identified between the efficiency and the average trophic level of the vessels.

When a VRS model is run with an egalitarian approach, a great distortion in the results obtained was observed (see Table 3). The average efficiency increases from 33.3\%3 $24.9 \%$ using CRS to $45.6 \% \pm 12.1 \%$ using VRS. To a certain extent, this change is attributable to the fact that the amount of efficient DMUs also increased from three (DMUs 9, 16 and 23) to six (DMUs 9, 11, 16, 23, 29 and 31). Consequently, the VRS model enhances the efficiency of the sample by 27\%. Some authors, such as Murillo-Zamorano (2004) [35], state that since the constraint set for CRS is less restrictive (the convexity constraint is absent) than in the VRS formulation, lower efficiency scores are possible and, therefore, more units are declared efficient for a VRS envelope surface. Moreover, the convexity constraint added in the VRS 
1 simply guarantees that each DMU is only compared to others of similar size, explaining the

2 similar results for the I and $\mathrm{H}$ matrices regardless of the selected approach. In contract, for the egalitarian matrix, the VRS model seems to be more convenient from a mathematical point of view. Nevertheless, considering that the unit of reference (DMU) is in all cases the fishing vessel, and considering that the fishing vessels inventoried in this study have all very similar characteristics, we consider that the use of the CRS approach should prevail.

7

8

To a great extent, the existing LCA+DEA literature describes inputs and outputs in the DEA matrices considering nominal values that, theoretically, are known in advance [36] [37]. In other words, this would imply that there is no uncertainty associated to the reported input/output values. Nevertheless, what is not taken into consideration in many of these studies, including those linked to the eco-efficiency of fishing fleets, is the fact that despite these values being treated as real, they are subject to epistemic uncertainties in data quality and availability [38]. Moreover, certain input/output values are not even direct measurements, but are extracted from complex datasets adapted from Life Cycle Inventories (LCIs). However, it could be argued that the use of the latter modelling choice is only carried out whenever the direct use of raw data is not possible [13].

The lack of detailed uncertainty modelling in LCA+DEA studies can be further justified by the fact that the intended virtual environmental gains that are estimated do not correspond to an effort to make inefficient DMUs efficient through innovation or technological leaps. On the contrary, LCA+DEA studies act as diagnostic tools that point out environmental inefficiencies through comparison with similar units of operations (i.e., DMUs), without 
1 empirically linking the inefficiency with a technological gap or a ecosystemic constraint. The selection of differentiated environmental damage perspectives throughout the

3 LCA+DEA method, which are based on different cultural perspectives, can, as depicted in 4 Figure 4, create relevant distortions in terms of the identification of efficient/inefficient DMUs 5 and, consequently, in the definition of robust target (virtual) environmental gains.

Figure 4 compares the current GWP of the different DMUs with the target GWP

7 calculated in step IV. It presents the environmental gains that would be observed in these

8 DMUs if they were to operate under the efficient conditions projected in each of the computed 9 matrices. The selection of DMUs in Figure 4 was performed based on the following criteria: i) 10 similar efficiencies were observed across the three matrices (DMUs 8 and 22); ii) at least one 11 of the perspectives deemed the DMU efficient (DMUs 9, 16 and 20); and, iii) efficiency values across matrices were substantially different (DMUs 14 and 29). In addition, Figure 4 also shows the relative efficiency of the average vessel. The environmental reduction of the average vessel was similar for all three perspectives/matrices, ca. 70\%, which is in line with the average vessel efficiency values of just over $30 \%$ presented above. As observed with the efficiency values, the environmental reduction of the DMUs when I and $\mathrm{H}$ perspectives were used was very similar ranging between $45 \%$ and $85 \%$, whereas the target GWP reduction when the E approach was employed was similar to I and $\mathrm{H}$ only when the efficiency values were very similar (i.e., DMUs 8 and 22). The egalitarian approach presented the highest potential reduction (91\%), when the DMU was efficient using I and $\mathrm{H}$ perspectives. 
2 sources of uncertainty that may appear and propagate throughout the LCA+DEA method,

3 which have not been quantified in the current study, there are a series of predefined cultural

4 theories that can have a predetermined effect on the final results. In this sense, LCA+DEA has

5 developed as a method based on input/output flows related to the technosphere, with the aim

6 of supporting decision-making in eco-efficiency [37]. This has led to a pervasive use of this

7 method based on modelling of market information, which in most cases fails to account for the

8 inherent changes in environmental flows and, ultimately, leads to the fact that the human

9 economy is constrained by biocapacity [39]. Nonetheless, despite the tendency to identify the

10 LCA+DEA method to eco-efficiency, it was considered that this method is flexible enough to

11 offer a wider array of options to model environmental benchmarks. Therefore, depending on

12 the approach used to analyze the LCI data, it could take into account aspects related to the

13 ecosphere. The latter perspective would allow obtaining a more integrated analysis in

14 compliance with the natural flows of material and energy [40].

\section{4. Conclusions}

To date, the limited development of the LCA+DEA methodology as compared to the

17 LCA or the DEA methodologies separately has covered the needs of specific scientific questions and aided in the identification of potential benchmarks in order to mitigate environmental impacts through the minimization of energy and material flows. However, LCA+DEA still lacks of a complex methodological framework which would allow the optimization of its full potential.

The current study demonstrated that the selection of energy-, mass-, or carbon contentbased outputs to represent fish landings in the DEA matrices can have a substantial influence on the final results in LCA+DEA computation. For instance, in the particular case of fishing 
1 the health of fishing stocks and the trophic complexity of the ecosystems. In this sense, it is

2 recommended that future LCA+DEA studies that aim at computing environmental impact

3 benchmark targets through resource use minimization should enhance the relevance of their

4 results by providing deeper sensitivity analysis. Output selection in the DEA matrices, linked

5 to cultural theories or other assumptions, may just be one example of numerous parameters that

6 are prone to interpretation from a numerical perspective.

Regardless of the uncertainty in the results observed in the current study, which can be

8 solved to a great extent through the use of sensitivity analysis, a shift from a deterministic to a stochastic approach when combining LCA and DEA is a current need in order to be able to assess the robustness and significance of the results obtained with this method.

\section{Acknowledgements}

The authors thank the Ministry of Economy and Competitiveness of the Spanish Government for their financial support via the project GeSAC-Conserva: Sustainable Management of the Cantabrian Anchovies (CTM2013-43539-R) and Yago Lorenzo-Toja, Sara González-García and Lucía Lijó for valuable scientific exchange. Jara Laso thanks the Ministry of Economy and Competitiveness of Spanish Government for their financial support through the research fellowship BES-2014-069368 and the Ministry of Rural Environment, Fisheries and Food of Cantabria for support with data collection. Reviewers are also thanked for the valuable and detailed suggestions.

\section{References}

[1]. Gascuel, D., Coll, M., Fox, C., Guénette, S., Guitton, J., Kenny, A., Knittweis, L., Rasmus-Nielsen, J., Piet, G., Raid, T., Travers-Trolet, M., Shephard, S., (2014). Fishing impact and environmental status in European seas: a diagnosis from stock assessments and ecosystem indicators. Fish and Fisheries, 17 (1), 31-55.

[2]. Pauly, D., Zeller, D., (2016). Catch reconstructions reveal that global marine fisheries catches are higher than reported and declining. Nature Communications, 7.

[3]. Tingley, D., Pascoe, S., Coglan, L., (2005). Factors affecting technical efficiency in fisheries: stochastic production frontier versus data envelopment analysis approaches. 
Fisheries Research, 73, 363-376.

[4]. Tingley, D., Pascoe, S., Mardle, S., (2003). Estimating capacity utilization in multipurpose, multi-métier fisheries. Fisheries Research, 63 (1), 121-134.

[5]. FAO, (2003). Measuring and assessing capacity in fisheries - 2. Issues and methods. Available at: http://www.fao.org/docrep/006/Y5027E/y5027e00.htm\#Contents.

[6]. Vázquez-Rowe, I., Iribarren, D., Moreira, M. T., Feijoo, G., (2010). Combined application of life cycle assessment and data envelopment analysis as a methodological approach for the assessment of fisheries. The International Journal of Life Cycle Assessment, 15(3), 272-283.

[7]. Vázquez-Rowe, I., Iribarren, D., Hospido, A., Moreira, M.T., Feijoo, G. (2011). Computation of Operational and Environmental Benchmarks within Selected Galician Fishing Fleets. Journal of Industrial Ecology, 15(5), 776-795.

[8]. Iribarren, D., Vázquez-Rowe, I., Moreira, M. T., Feijoo, G., (2010). Further potentials in the joint implementation of life cycle assessment and data envelopment analysis. Science of the Total Environment, 408(22), 5265-5272.

[9]. Vázquez-Rowe, I., \& Iribarren, D., (2015). Review of Life-Cycle Approaches Coupled with Data Envelopment Analysis: Launching the CFP + DEA Method for Energy Policy Making. The Scientific World Journal, 2015.

[10]. Vázquez-Rowe, I., Villanueva-Rey, P., Iribarren, D., Moreira, M. T., Feijoo, G., (2012). Joint life cycle assessment and data envelopment analysis of grape production for vinification in the Rías Baixas appellation (NW Spain). Journal of Cleaner Production, 27, 92-102.

[11]. Ziegler, F., Hornborg, S., Green, B. S., Eigaard, O.R., Farmery, A.K., Hammar, L., Vázquez-Rowe, I., (2016). Expanding the concept of sustainable seafood using Life Cycle Assessment. Fish and Fisheries, 17,1073-1093.

[12]. Avadí, A., Fréon, P., (2013). Life cycle assessment of fisheries: a review for fisheries scientist and managers. Fisheries Research, 143, 21-38.

[13]. Avadí, A., Vázquez-Rowe, I., Fréon, P., (2014). Eco-efficiency assessment of the Peruvian anchoveta steel and wooden fleets using the LCA+DEA framework. Journal of Cleaner Production, 70, 118-131.

[14]. Cooper, WW., Seifor, LM., Zhu, J., (2004). Handbook on Data Envelopment Analysis. Springer.

[15]. Odum, H.T., (1988). Self-organization, transformity and information. Science 242: 1132-1139.

[16]. Odum, H.T., (1996). Environmental accounting: emergy and environmental decision making. New York: John Wiley \& Sons. ISBN: 978-0-471-11442-0.

[17]. De Schryver, A.M., van Zelm, R., Humbert, S., Pfister, S., McKone, T.E., Huijbregts, M.A.J., (2011). Value choices in Life Cycle Impact Assessment of Stressors causing Human Health Damage. Journal Industrial Ecology, 15 (5), 796-815.

[18]. De Schryver, A.M., (2010). Value choices in life cycle impact assessment. PhD-Thesis. Radboud University, Nijmegen.

[19]. Van Asselt, M.B.A., Rotmans, J., (1996). Uncertainty in perspective. Global Environmental Change, 6 (2): 121-157.

[20]. Janssen, M., Rotmans, J., (1995). Allocation of fossil $\mathrm{CO}_{2}$ emission rights quantifying 
cultural perspectives. Ecological Economics, 13, 65-79.

[21]. Goedkoop, M., Spriensma, R., (1999). The Eco-indicator 99: A damage oriented method for Life Cycle Impact Assessment Methodology. The Netherlands, PRé Consultants b.v.

[22]. Frischknecht, R., Braunschweig, A., Hofstetter, P., Suter, P., (2000). Human health damages due to ionising radiation in life cycle impact assessment. Environmental Impact Assessment Review, 20, 159-189.

[23]. De Schryver, A.M., Humbert, S., Huijbregts, M.A.J., (2013). The influence of value choices in life cycle impact assessment of stressors causing human health damage. International Journal of Life Cycle Assessment, 18:698-706.

[24]. Pushkar, S., (2014). Using Eco-Indicator 99 to Evaluate Building Technologies under Life Cycle Assessment Uncertainties. Journal of Architectural Engineering, 20 (2), 04013010.

[25]. Goedkoop, M., Heijungs, R., Huijbregts, M., De Schryver, A., Struijs, J., van Zelm, R., (2009). ReCIPE 2008. A life impact assessment method which comprises harmonized category indicators at the midpoint and the endpoint level. Report I: Characterisation.

[26]. González-García, S., Villanueva-Rey, P., Belo, S., Vázquez-Rowe, I., Moreira, M.T., Feijoo, G., Arroja, L., (2015). Cross-vessel eco-efficiency analysis. A case study for purse seining fishing from North Portugal targeting Eurpean pilchard. International Journal of Life Cycle Assessment, 20 (7), 1019-1032.

[27]. Lozano, S., Iribarren, D., Moreira, M.T., Feijoo, G., (2009). The link between operational efficiency and environmental impacts. A joint application of Life Cycle Assessment and Data Envelopment Analysis. Science of the Total Environment, 407 (5), 1744-1754.

[28]. Laso, J., Vázquez-Rowe, I., Margallo, M., Crujeiras, R.M., Irabien, A., Aldaco, R., (2017). Life cycle assessment of European anchovy (Engraulis encrasicolus) landed by purse seine vessels in northern Spain. International Journal of Life Cycle Assessment, DOI: 10.1007/s11367-017-1318-7.

[29]. Goedkoop, M., Oele, M., Leijting, J., Ponsioen, T., Meijer, E., (2016). Introduction to LCA with SimaPro 8. PRé Consultants, Amersfoort.

[30]. National Institute for Public Health and the Environment. Ministry of Health, Welfare and Sport. ReCIPE model - Characterization and normalization factors. Available at: http://www.rivm.nl/Onderwerpen/L/Life_Cycle_Assessment_LCA/Downloads/Document en/6_ReCiPe111:ivzzJqqYT0ytBW7zKdCSFw.

[31]. Parker, R., (2011). Measuring and characterizing the ecological foot-print and life cycle environmental cost of Antartic Krill (Euphasia superb) products. M Sc Thesis. Dalhousie University, Canada.

[32]. Pauly, D., Christensen, V., (1995). Primary production required to sustain global fisheries. Nature, 374 (6519): 225-257.

[33]. Pesca de Galicia., (2017). Available at: http://www.pescadegalicia.gal/. Accessed March 2017.

[34]. Saitech (2017). Available at: http://www.saitech-inc.com/products/prod-dsp.asp.

[35]. Murillo-Zamorano, L.R., (2004). Economic efficiency and frontier techniques. Journal of Economic Surveys, 18, 33-78 
1 [36]. Lorenzo-Toja, Y., Vázquez-Rowe, I., Chenel, S., Marín-Navarro, D., Moreira, M. T., 2 Feijoo, G., (2015). Eco-efficiency analysis of Spanish WWTPs using the LCA+DEA 3 method. Water Research, 68, 651-666.

4 [37]. Lorenzo-Toja, Y., Vázquez-Rowe, I., Marín-Navarro, D., Crujeiras, R.M., Moreira, 5 M.T., Feijoo, G. (2017) Dynamic environmental efficiency assessment for wastewater treatment plants. International Journal of Life Cycle Assessment, DOI 10.1007/s11367017-1316-9.

[38]. Pascoe, S., Herrero, I., Mardle, S., (2001) Identifying mis-reporting in fisheries output data using DEA. Paper presented at the VII European productivity and efficiency workshop, Oviedo, Spain, 25-27 September 2001.

[39]. Pelletier, N., Tyedmers, P., (2011). An ecological economic critique of the use of market information in life cycle assessment research. Journal of Industrial Ecology, 15(3), 342-354.

[40]. Rockström J., W. Steffen, K. Noone, A. Persson, F.S. Chapin 3rd, E.F. Lambin, T.M. Lenton, et al. 2009. A safe operating space for humanity. Nature 461: 472-475.

[41]. Bösch, M.E., Hellweg, S., Huijbregts, M., Frischknecht, R., (2007). Applying cumulative exergy demand (CExD) indicators to the ecoinvent database. International Journal of Life Cycle Assessment, 12(3), 181-190.

19

20

21

22

23

24 